\title{
Common fixed points of two finite families of nonexpansive mappings by iterations
}

\author{
HAFIZ FUKHAR-UD-DIN ${ }^{1,2}$
}

\section{ABSTRACT.}

We study a Mann type iterative scheme for two finite families of nonexpansive mappings and establish $\triangle-$ convergence and strong convergence theorems. The obtained results are applicable in uniformly convex Banach spaces (linear domain) and CAT (0) spaces (nonlinear domain) simultaneously.

Acknowledgement. The author is grateful to King Fahd University of Petroleum \& Minerals for supporting research project IN121055.

\section{REFERENCES}

[1] Abbas, M. and Khan, S. H., Some $\triangle$-convergence theorems in CAT (0) spaces, Hacet. J. Math. Stat., 40 (2011), No. 4, 563-569

[2] Bauschke, H. H. and Combettes, P. L., Convex Analysis and Monotone Operator Theory in Hilbert Spaces, Springer-Verlag, New York (2011)

[3] De Marr, R., Common fixed points for commuting contraction mappings, Pacific J. Math., 13 (1963), 1139-1141

[4] Fukhar-ud-din, H., Existence and approximation of fixed points in convex metric spaces, Carpathian J. Math., 30 (2014), 175-185

[5] Fukhar-ud-din, H., One step iterative scheme for a pair of nonexpansive mappings in a convex metric space, Hacettepe Journal of Mathematics and Statistics, Accepted (2014)

[6] Yildirim, I., Khan, S. H. and Ozdemir, M., Some fixed point results for uniformly quasi-Lipschitzian mappings in convex metric spaces, Journal of Nonlinear Analysis and Optimization (JNAO), 4(2013), 143-148

[7] Ishikawa, S., Fixed points by a new iteration method, Proc. Amer. Math. Soc., 44 (1974), 147-150

[8] Khan, S. H. and Fukhar-ud-din, H., Weak and strong convergence of a scheme with errors for two nonexpansive mappings, Nonlinear Analysis, 61 (2005), 1295-1301

[9] Khan, A. R., Khamsi, M. A. and Fukhar-ud-din, H., Strong convergence of a general iteration scheme in CAT(0) spaces,Nonlinear Anal., 74 (2011), 783-791

[10] Khan, S. H., Yildirim, I. and Ozdemir, M., Convergence of an implicit algorithm for two families of nonexpansive mappings, Comp. Math. Appl., 59 (2010), 3084-3091

[11] Kirk, W. and Panyanak, B., A concept of convergence in geodesic spaces, Nonlinear Anal., 68 (2008), 3689-3696

[12] Kuczumow, T., An almost convergence and its applications, Ann. Univ. Mariae Curie-Sklodowska Sect. A, 32 (1978), 79-88

[13] Kuhfittig, P. K. F., Common fixed points of nonexpansive mappings by iteration, Pacific J. Math., 97 (1981), 137-139

[14] Mann, W. R., Mean value methods in iterations, Proc. Amer. Math. Soc., 4 (1953), 506-510

[15] Shimizu, T. and Takahashi, W., Fixed points of multivalued mappings in certain convex metric spaces, Topol. Methods Nonlinear Anal., 8 (1996), 197-203

[16] Takahashi, W., A convexity in metric spaces and nonexpansive mappings, Kodai Math. Sem. Rep., 22 (1970), 142-149

Received: 07.08.2014; In revised form: 26.02.2015; Accepted: 28.02.2015

2010 Mathematics Subject Classification. 47H09, 47H10, 49M05.

Key words and phrases. Convex metric space, common fixed point, nonexpansive mapping, strong convergence, $\triangle$-convergence. 
${ }^{1}$ Department of Mathematics and Statistics

King Fahd University of Petroleum and Minerals

DHAHran 31261, SAUdi ARABia

2 Department of Mathematics

THE ISLAMIA UNIVERSITY OF BAHAWALPUR

BAHAWALPUR 63100, PAKISTAN

E-mail address: hfdinekfupm.edu.sa, hfdin@yahoo.com 